\title{
A simplified mechanically based model for predicting partially drained behaviour of penetrometers and shallow foundations
}

\author{
G. T. HOULSBY* and M. J. CASSIDY†
}

\begin{abstract}
An analytical model is described for the behaviour of shallow foundations subjected to partially drained vertical penetration. The model is based on a simplified mechanical approach, allowing the calibration of model parameters for different foundation shape, size and soil conditions. As shown through simple examples, the resulting model exhibits (with some limitations) behaviour that closely resembles that obtained from geotechnical centrifuge experiments of a T-bar penetrometer and a circular spudcan footing installed at a variety of rates. An extension of the model to combined vertical and horizontal loading is also possible, although this would require further calibration with experimental data. The model retains a simplicity that may find application in the coupled analysis of offshore structures with foundations that are subjected to loading under different rates and drainage.
\end{abstract}

KEYWORDS: bearing capacity; footings/foundations; offshore engineering; plasticity; silts

ICE Publishing: all rights reserved

\section{INTRODUCTION}

It is well established that the bearing capacity of shallow foundations is related to the drainage conditions established in the surrounding soil. Under purely vertical load and in a single layer, recent tests at different penetration rates have provided evidence of this change in capacity. Backbone curves that normalise resistance against a normalised velocity have been established: initially for circular footings by Finnie (1993) and, more recently, for T-bar, ball and piezocone penetrometer site characterisation tests in unpublished data of Watson and Suemasa (quoted by House et al. (2001) and Chung et al. (2006)) and Randolph \& Hope (2004), Schneider et al. (2007) and Yafrate \& DeJong (2007). An illustration of the vertical capacity with changing penetration rates is provided in Fig. 1, with Fig. 1(c) showing a common feature (at least for loose to medium dense non-dilating soils) of an increase in capacity as the normalised velocity $v D / c_{\mathrm{V}}$ decreases ( $v$ is the penetration velocity, $D$ is the equivalent diameter of the footing or penetrometer and $c_{\mathrm{V}}$ is the coefficient of consolidation). Experiments have shown fully undrained behaviour for normalised velocities greater than about 30, drained for less than about 0.01 and partially drained for values in between the two (Chung et al., 2006). Predicting the backbone curve of Fig. 1(c) is more complex for silty soils, as discussed by Schneider et al. (2007).

Though similar behaviour is expected under combined vertical and horizontal loads, very little experimental evidence is available. Yield surfaces, written directly in terms of the combined loading, have been established for drained (e.g. Houlsby \& Cassidy, 2002; Bienen et al., 2006) and undrained behaviour (e.g. Martin \& Houlsby, 2001;

Manuscript received 16 June 2011; first decision 19 July 2011; accepted 2 August 2011.

Published online at www.geotechniqueletters.com on 22 August 2011.

*Department of Engineering Science, Oxford University, Oxford, UK

†Centre for Offshore Foundation Systems, University of Western Australia, Crawley, Australia
Hodder \& Cassidy, 2010). This approach has led to complete force-resultant plasticity models describing load-displacement behaviour under general loading events. However, the footing behaviour has still been represented as purely drained or undrained, with the theoretical framework of models that span from one to the other and consistently account for different loading rates not yet clearly established. They are required, however, with offshore applications often involving partially drained conditions. The displacement of on-bottom pipelines and the large conical spudcans of mobile 'jackup' platforms in some silty soils are current topical examples.

\section{PROPOSED MODEL FOR VERTICAL LOADING Mechanical analogy}

We consider first purely vertical loading and define the relationship between the vertical load $V$ (or equivalently the bearing reaction $q=V / A$ ) and the vertical displacement $w$ (see Fig. 1(a)). A schematic of the mechanical analogy of the behaviour is shown in Fig. 2. Table 1 details each model variable and provides typical parameter values.

The model can be considered as two sections connected in series. The upper part of Fig. 2 shows a spring and slider system, which represents the undrained response of the foundation: the spring represents the small elastic deformation and the slider represents the plastic deformation $\alpha_{\mathrm{p}}$. The capacity of the slider is governed by a workhardening relationship. It is initially $c$, representing the (possibly small) capacity at the soil surface, but then increases as a function of the footing penetration. The particular form of this function governs many features of the subsequent model.

The lower part of Fig. 2 shows a second spring, which represents the additional elastic deformation that occurs during drained penetration. This spring acts in parallel with a dashpot, which represents the drainage processes in the soil: for rapid processes, the dashpot does not deform and there is no drained penetration. In principle, it would be possible to include a further element to represent drained plastic deformation, but it is found that most of the 


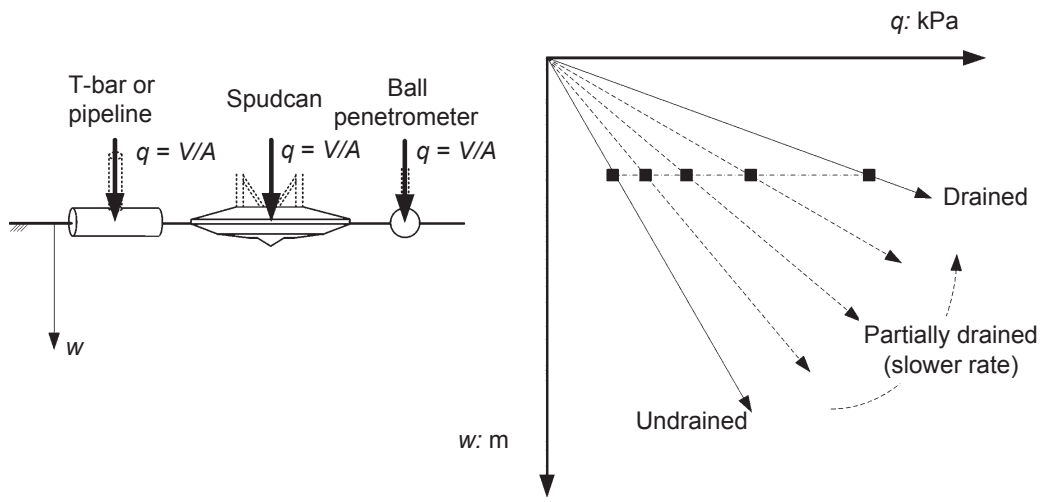

(a) (b)

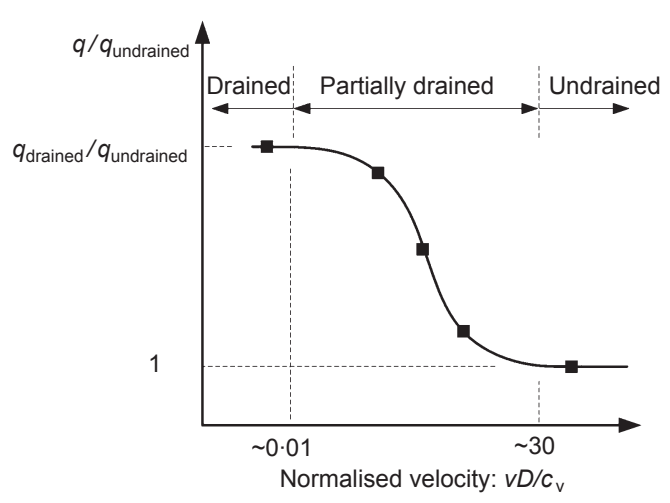

(c)

Fig. 1. Applications and drainage behaviour to be modelled: (c) normalised load against velocity

observed features of partially drained foundation response can be captured without introducing this further complication, so we do not pursue it here. Note, however, that the strength of the plastic slider is a function of $\alpha_{d}$, the amount of drained deformation. It is the inclusion of this term that captures the effect of increased capacity with consolidation.

The formulation of the model is based on the 'hyperplasticity' approach (Houlsby \& Puzrin, 2006). In this approach, a model may be completely defined by the specification of just two scalar functions: the Helmholtz free energy $(f)$ and

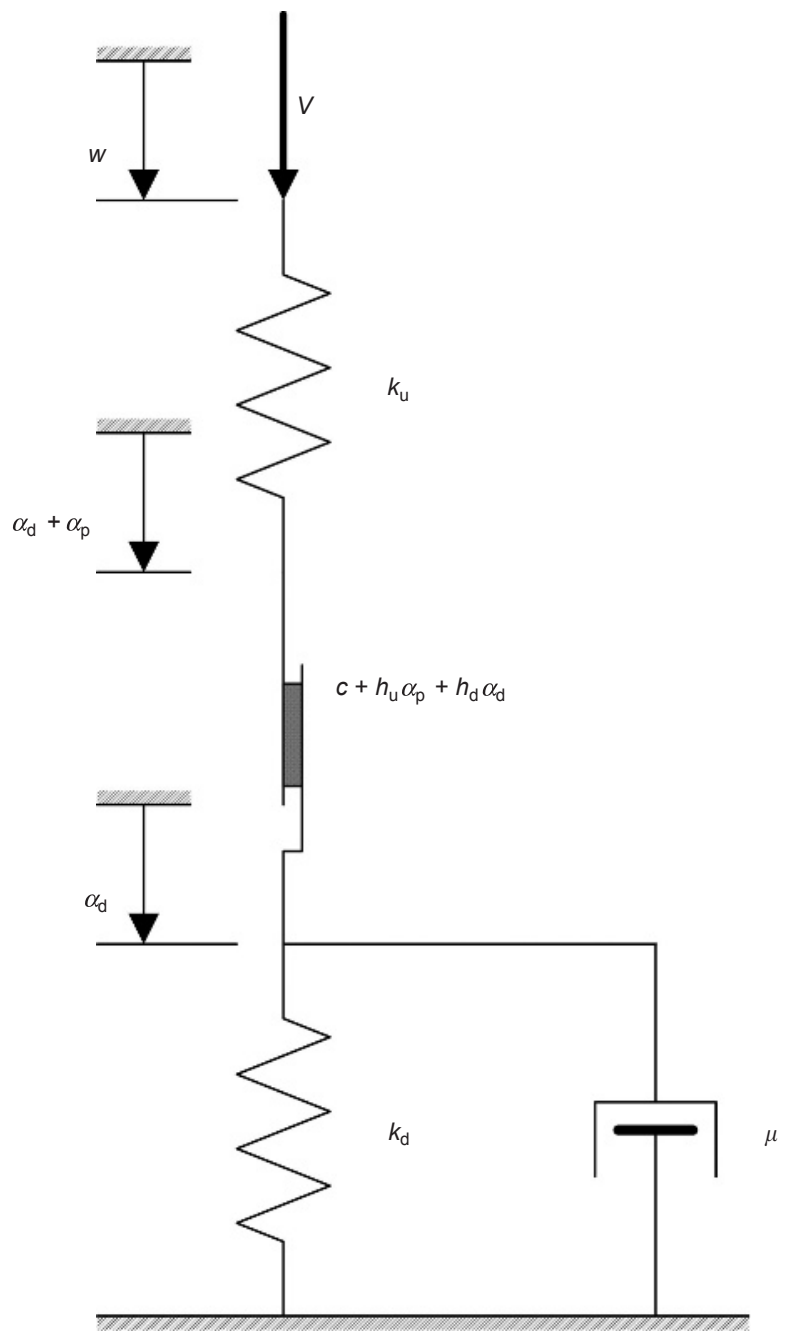

Fig. 2. Schematic illustration of equivalent mechanical model (a) applications; (b) vertical load-penetration with drainage;

the force potential $(d)$. The development of the model in a hierarchical manner is detailed in the accompanying annex to this paper, leading to the expressions for a model for partially drained vertical loading:

$$
\begin{aligned}
& f=\frac{k_{\mathrm{u}}}{2}\left(w-\alpha_{\mathrm{p}}-\alpha_{\mathrm{d}}\right)^{2}+\frac{k_{\mathrm{d}}}{2} \alpha_{\mathrm{d}}^{2} \\
& d=\mu \dot{\alpha}_{\mathrm{d}}^{2}+V_{\mathrm{o}}\left\langle\dot{\alpha}_{\mathrm{p}}\right\rangle
\end{aligned}
$$

in which $V_{\mathrm{o}}=c+h_{\mathrm{u}} \alpha_{\mathrm{p}}+h_{\mathrm{d}} \alpha_{\mathrm{d}}$. The annex also details further developments in which horizontal as well as vertical loading is introduced. The physical representation of the parameters of equations (1) and (2) are provided in Fig. 2 and their influence on behaviour is shown in Fig. 3.

In this model, the value assigned to the strength of the plasticity element, $V_{\mathrm{o}}=c+h_{\mathrm{u}} \alpha_{\mathrm{p}}+h_{\mathrm{d}} \alpha_{\mathrm{d}}$ is important. We have allowed for a term, $c$, which introduces a constant strength, and the two terms $h_{\mathrm{u}} \alpha_{\mathrm{p}}$ and $h_{\mathrm{d}} \alpha_{\mathrm{d}}$, which allow for increase in strength due to undrained plastic compression and due to the consolidation compression respectively. It is found that the relative response of the model during undrained/drained behaviour depends critically on relative values of the parameters $h_{\mathrm{u}}$ and $h_{\mathrm{d}}$. This particular expression for $V_{\mathrm{o}}$ is given for illustration only and, in principle, any form of the function $V_{\mathrm{o}}=V_{\mathrm{o}}$ $\left(\alpha_{\mathrm{p}}, \alpha_{\mathrm{d}}\right)$ could be used without changing the structure of the model.

\section{MODEL CALIBRATION}

The quality of the predictions derived from the above model depends clearly on the selection of the parameters $k_{\mathrm{u}}, k_{\mathrm{d}}, h_{\mathrm{u}}, d_{\mathrm{d}}, c$ and $\mu$.

Consider first the choice of $k_{\mathrm{u}}$, which defines the elastic relationship in the undrained condition ( $K_{\mathrm{ue}}$ in Fig. 3). Standard solutions for vertical loading of a rigid circular footing on an elastic half-space (e.g. Poulos \& Davis, 1974), together with an assumption of the soil's shear modulus $G$, could be used as a starting point in determining the parameter $k_{\mathrm{u}}$. For instance, to describe the relationship:

$$
q=\frac{V}{\pi R^{2}}=\frac{8}{\pi(1-v)} \frac{G}{2 R} w
$$

where $v$ is Poisson's ratio, the value of $k_{\mathrm{u}}$ is given by:

$$
k_{\mathrm{u}}=\frac{8}{\pi(1-v)} \frac{G}{2 R}
$$


Table 1. Properties used in the model

\begin{tabular}{|c|c|c|c|c|c|c|}
\hline & \multirow[b]{2}{*}{ Explanation } & \multirow{2}{*}{$\begin{array}{l}\text { Dimens- } \\
\text { ion }\end{array}$} & \multirow{2}{*}{$\begin{array}{l}\text { Constr- } \\
\text { aints }\end{array}$} & \multirow[b]{2}{*}{ Notes } & \multicolumn{2}{|c|}{ Value used in example } \\
\hline & & & & & T-bar & Spudcan \\
\hline$k_{\mathrm{u}}$ & $\begin{array}{l}\text { Elastic stiffness factor } \\
\text { (undrained) }\end{array}$ & $\mathrm{F} / \mathrm{L}^{3}$ & & $\begin{array}{l}k_{\mathrm{u}} \text { can be fit using a rigidity index, such that } \\
\text { the shear modulus } G=I_{\mathrm{R}} S_{\mathrm{u}} \text {, together with } \\
\text { an elastic matrix coefficient, provide the } \\
\text { undrained elastic stiffness } K_{\mathrm{ue}} \text { sought }\end{array}$ & $\begin{array}{l}2400 \\
\mathrm{kPa} / \mathrm{m}\end{array}$ & $\begin{array}{l}200 \\
\mathrm{kPa} / \mathrm{m}\end{array}$ \\
\hline$k_{\mathrm{d}}$ & Elastic stiffness factor (drained) & $\mathrm{F} / \mathrm{L}^{3}$ & $k_{\mathrm{d}}>k_{\mathrm{u}}$ & $\begin{array}{l}k_{\mathrm{d}} \text { can be assumed as a ratio of drained to } \\
\text { undrained elastic stiffness }\end{array}$ & $\begin{array}{l}4800 \\
\mathrm{kPa} / \mathrm{m}\end{array}$ & $\begin{array}{l}400 \\
\mathrm{kPa} / \mathrm{m}\end{array}$ \\
\hline$c$ & Initial plastic yield strength & $\mathrm{F} / \mathrm{L}^{2}$ & $c>0$ & $\begin{array}{l}\text { Initial resistance in mechanical slider. A low } \\
\text { value represents little mudline strength } \\
\text { (normally consolidated), whereas a high } \\
\text { value represents a high strength (or over- } \\
\text { consolidation) }\end{array}$ & $0.5 \mathrm{kPa}$ & $0.5 \mathrm{kPa}$ \\
\hline$h_{\mathrm{u}}$ & $\begin{array}{l}\text { Applied stress strength increase } \\
\text { (undrained) }\end{array}$ & $\mathrm{F} / \mathrm{L}^{3}$ & & $\begin{array}{l}\text { Factor accounting for displacement hard- } \\
\text { ening within the undrained spring-slider } \\
\text { system }\end{array}$ & $\begin{array}{l}10 \cdot 5 \\
\mathrm{kPa} / \mathrm{m}\end{array}$ & $\begin{array}{l}9 \cdot 5 \\
\mathrm{kPa} / \mathrm{m}\end{array}$ \\
\hline$h_{\mathrm{d}}$ & $\begin{array}{l}\text { Applied stress strength increase } \\
\text { (drained) }\end{array}$ & $\mathrm{F} / \mathrm{L}^{3}$ & $h_{\mathrm{d}}>h_{\mathrm{u}}$ & $\begin{array}{l}\text { Factor accounting for displacement hard- } \\
\text { ening within the drained spring-dashpot } \\
\text { system. For the drained stiffness to be larger } \\
\text { than the undrained, } h_{\mathrm{d}}>h_{\mathrm{u}} \text {. }\end{array}$ & $\begin{array}{l}3552 \cdot 8 \\
\mathrm{kPa} / \mathrm{m}\end{array}$ & $\begin{array}{l}405 \cdot 3 \\
\mathrm{kPa} / \mathrm{m}\end{array}$ \\
\hline$\mu$ & $\begin{array}{l}\text { Viscosity of drained contribu- } \\
\text { tion }\end{array}$ & $\left(\mathrm{F} / \mathrm{L}^{3}\right) \mathrm{T}$ & & $\begin{array}{l}\text { Viscosity is used to relate the level of } \\
\text { drainage, with higher values causing less } \\
\text { drained behaviour for the same loading rate. } \\
\text { The property can be fit to the required } \\
\text { partially drained history, such as shown for } \\
\text { the normalised velocity } v D / c_{\mathrm{V}} \text { behaviour of } \\
\text { Figs } 1 \text { (c) and (5) }\end{array}$ & $\begin{array}{l}1 \cdot 1 \times 10^{11} \\
(\mathrm{kPa} / \mathrm{m}) \mathrm{s}\end{array}$ & $\begin{array}{l}1 \cdot 5 \times 10^{7} \\
(\mathrm{kPa} / \mathrm{m}) \mathrm{s}\end{array}$ \\
\hline
\end{tabular}

Other elastic solutions, as described for various footing types and conditions by Doherty \& Deeks (2003), could be used for more complex conditions. The elastic parameter $k_{\mathrm{d}}$ could be determined in a similar manner. However, noting that the elastic stiffness is:

$$
K_{\mathrm{de}}=\frac{k_{\mathrm{u}} k_{\mathrm{d}}}{k_{\mathrm{u}}+k_{\mathrm{d}}}
$$

and that $K_{\mathrm{de}} / K_{\mathrm{ue}}$ is typically about $0 \cdot 65$, the value $k_{\mathrm{d}} \approx 2 k_{\mathrm{u}}$ is appropriate for most applications.

The choice of $h_{\mathrm{u}}$ and $h_{\mathrm{d}}$ requires fitting the plastic stiffness desired. After the initial sliding capacity $c$ is exceeded, the undrained plastic stiffness (see Fig. 3) is:

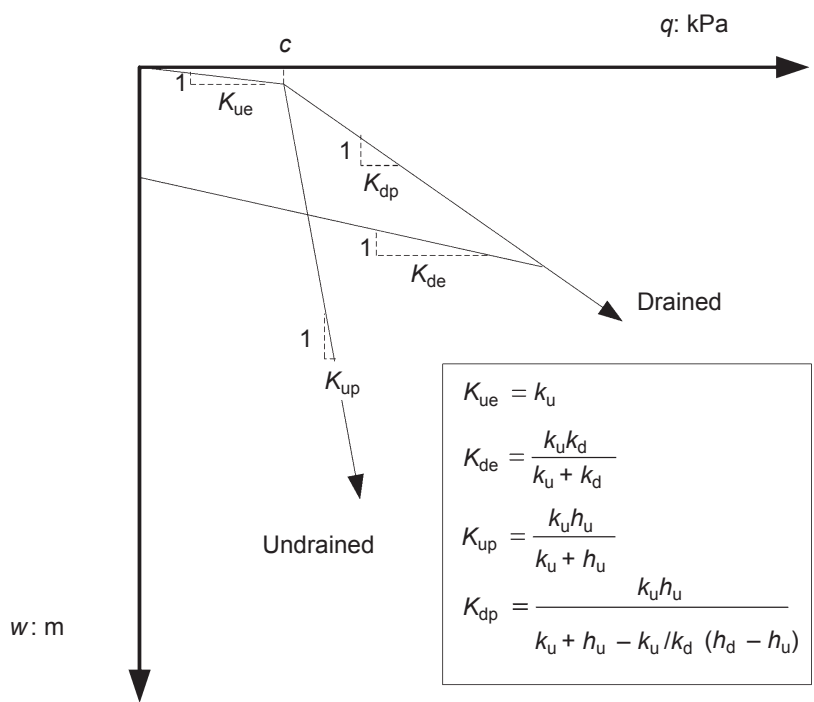

Fig. 3. Behaviour of model

$$
K_{\mathrm{up}}=\frac{k_{\mathrm{u}} h_{\mathrm{u}}}{k_{\mathrm{u}}+h_{\mathrm{u}}}
$$

and the purely drained plastic stiffness is:

$$
K_{\mathrm{dp}}=\frac{k_{\mathrm{u}} h_{\mathrm{u}}}{k_{\mathrm{u}}+h_{\mathrm{u}}-\left(k_{\mathrm{u}} / k_{\mathrm{d}}\right)\left(h_{\mathrm{d}}-h_{\mathrm{u}}\right)}
$$

Bearing capacity theory can be used to estimate the required stiffness and, therefore, the values of $h_{\mathrm{u}}$ and $h_{\mathrm{d}}$.

The value of $\mu$ is used to describe the rate of drainage and, therefore, the relative contribution of the drained spring to the mechanical system. For instance, high values of $\mu$ cause less drained behaviour for the same loading rate. The choice of viscosity $\mu$ is therefore the least intuitive of the model parameters. However, its value can be fitted to the required drained history response. For instance, it can be calibrated against a backbone curve of normalised velocity $v D / c_{\mathrm{v}}$ behaviour, such as that displayed in Fig. 1(c). In doing so, $\mu$ also affects the $v D / c_{\mathrm{v}}$ value of transition into the partially drained response.

It is important to note that the observed behaviour of higher plastic stiffness on drained as compared with undrained behaviour cannot be modelled by the presence of the viscous element alone, as this always makes the undrained response stiffer. It is the presence of the term in $\alpha_{\mathrm{d}}$ in the expression for $V_{\mathrm{o}}$ that defines the realistic response.

\section{Example: comparison with $t$-bar penetration tests}

The ability of the model to simulate penetration of a footing at different rates is first assessed against a series of T-bar penetration tests of different fixed rates. As reported by House et al. (2001), the tests were conducted in normally consolidated Kaolin clay in a drum centrifuge. The T-bar was $5 \mathrm{~mm}$ in diameter and $20 \mathrm{~mm}$ long. With tests conducted at an acceleration of 100 times that of Earth's gravity, an equivalent prototype diameter is $0.5 \mathrm{~m}$ and 


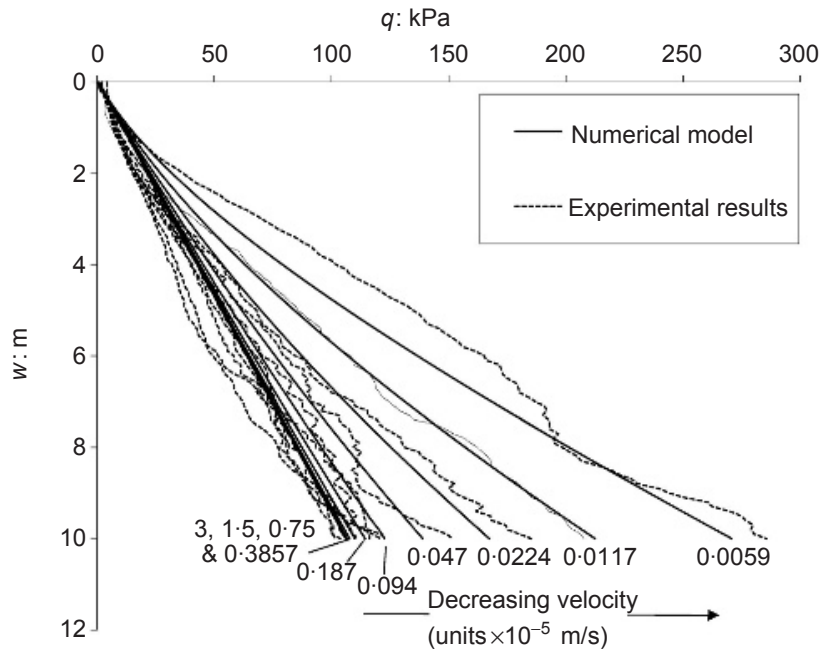

Fig. 4. Comparison of model with experimental T-bar penetrations for different rates

length $2 \cdot 0 \mathrm{~m}$. The fastest test was conducted at $3 \mathrm{~mm} / \mathrm{s}$, the limiting speed of the actuator, with another nine tests conducted at rates successively half of the last, with the slowest test at $0.0059 \mathrm{~mm} / \mathrm{s}$. With the centrifuge at $100 \mathrm{~g}$, the scaling factor for diffusion time is $1 / 100^{2}$ and for distance 1/100 (Garnier et al., 2007). As water was used in the tests of House et al. (2001), the prototype velocity is therefore $1 / 100$ that used in the model. A $c_{\mathrm{v}}$ value was estimated at $3.3 \mathrm{~m}^{2} /$ year (House et al., 2001), resulting in normalised velocities $v D / c_{\mathrm{v}}$ of between 143 and $0 \cdot 28$.

The measured bearing profiles for the experiments are shown in Fig. 4, though all results are reported here in equivalent prototype dimensions. The fastest four tests provided similar behaviour, within the experimental variability, before the slower tests provided higher responses. Assuming a T-bar bearing capacity factor of $N_{\mathrm{c}}=10 \cdot 5$, the undrained shear strength profile of the normally consolidated clay was approximately $1 \mathrm{kPa} / \mathrm{m}$ (and $K_{\text {up }}$ best estimated as $10.5 \mathrm{kPa} / \mathrm{m}$ ). Unfortunately, these tests did not extend into fully drained conditions. However, based on the previous experiences of Watson and Suemasa as reported by House et al. (2001) and Chung et al. (2006), a backbone curve assuming a ratio of drained to undrained capacity of 3.77 was fitted to the data and is represented in Fig. 5.

The T-bar tests of House et al. (2001) were retrospectively simulated with $k_{\mathrm{u}}=2400 \mathrm{kPa} / \mathrm{m}, k_{\mathrm{d}}=4800 \mathrm{kPa} / \mathrm{m}, h_{\mathrm{u}}=$ $10.5 \mathrm{kPa} / \mathrm{m}, h_{\mathrm{d}}=3552.8 \mathrm{kPa} / \mathrm{m}, c=0.5 \mathrm{kPa}$ (nominally zero) and $\mu=1 \cdot 1 \times 10^{11}(\mathrm{kPa} / \mathrm{m}) \mathrm{s}$. Figure 4 shows the computed response for a prototype $0.5 \mathrm{~m} \mathrm{~T}$-bar penetrated $10 \mathrm{~m}$ at rates of $3.0 \times 10^{-5} \mathrm{~m} / \mathrm{s}$ to $5 \cdot 9 \times 10^{-8} \mathrm{~m} / \mathrm{s}$. A close match is shown for this set of parameter values. As the testing programme was in a normally consolidated soil, with an assumption of no mudline strength being reasonable, the value of $c$ was taken as a value close to zero. Therefore, the initial purely elastic section was limited, and is too small to see on Fig. 4. However, the change in the response from predominantly undrained to drained can be clearly observed in the figure, as the capacity obtained increases with each halving of the rate (from the fifth test at a velocity $0 \cdot 1875 \times 10^{-5} \mathrm{~m} / \mathrm{s}$ and slower).

The excellent fit of the numerical results against the partially drained backbone curve is shown in Fig. 5. This is expected to be good, as the model parameters were chosen such that the ratio of the drained to undrained stiffness

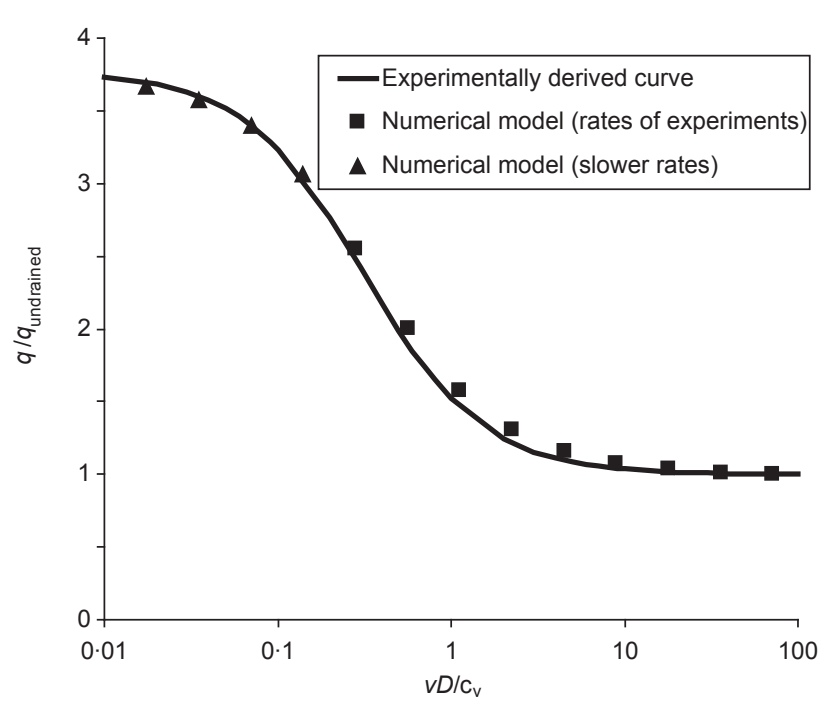

Fig. 5. Comparison of model and experimental data by normalised load versus velocity

$$
\frac{K_{\mathrm{dp}}}{K_{\mathrm{up}}}=\left[1-\frac{k_{\mathrm{u}}}{k_{\mathrm{d}}}\left(\frac{h_{\mathrm{d}}-h_{\mathrm{u}}}{k_{\mathrm{u}}+h_{\mathrm{u}}}\right)\right]^{-1}
$$

was set to the experimentally quoted value of $3 \cdot 77$ (House et al., 2001). However, the modelling of the degree of partial drainage for just the one $\mu$ value is pleasing, considering the simplicity of the model. To complete the backbone curve, a further four numerical simulations were conducted at slower rates; these are shown in Fig. 5. These show the ability of the model to approach the fully drained response along the quoted backbone curve.

\section{Example: comparison to spudcan penetration tests}

The versatility of the model is reinforced by retrospective simulation of centrifuge tests of a spudcan footing penetrating a calcareous silt (Cassidy, 2003). The centrifuge tests were conducted at $100 \mathrm{~g}$ with a $60 \mathrm{~mm}$ diameter model. The bearing resistance for fixed penetration rates of 0.033 and $1 \mathrm{~mm} / \mathrm{s}$, as well as a test initially at $0.033 \mathrm{~mm} / \mathrm{s}$ before being switched to $1 \mathrm{~mm} / \mathrm{s}$, is shown in Fig. 6 . In these tests, a 100 centistoke silicone oil was used as the pore fluid and therefore the prototype penetration rates are the same as those in the model. The coefficient of consolidation increased with vertical effective stress through the sample and, at the sample's mid-height, $c_{\mathrm{V}}$ was estimated to be $16.7 \mathrm{~m}^{2} /$ year. At this depth, normalised velocities $v D / c_{v}$ of 3.7 and 113.5 represented partially drained and fully undrained conditions.

The spudcan tests were simulated with $k_{\mathrm{u}}=200 \mathrm{kPa} / \mathrm{m}$, $k_{\mathrm{d}}=400 \mathrm{kPa} / \mathrm{m}, h_{\mathrm{u}}=9.5 \mathrm{kPa} / \mathrm{m}, h_{\mathrm{d}}=405.3 \mathrm{kPa} / \mathrm{m}, c=$ $0.5 \mathrm{kPa}$ (nominally zero) and $\mu=1.5 \times 10^{7}(\mathrm{kPa} / \mathrm{m}) \mathrm{s}$. Figure 6 shows a reasonable match between the experimental and computed response. However, the drained test clearly shows a non-linear variation of capacity with depth. The model has the flexibility to account for this by varying the function assigning the strength of the plasticity element. It is not necessary that $V_{\mathrm{o}}$ be the linear function with plastic displacements $\alpha_{p}$ and $\alpha_{d}$ that has been used so far. The model provides an improved fit to the experiments with the addition of a second-order term such that:

$$
V_{\mathrm{o}}=c+h_{\mathrm{u}} \alpha_{\mathrm{p}}+h_{\mathrm{d}} \alpha_{\mathrm{d}}+h_{\mathrm{d} 1} \alpha_{\mathrm{d}}^{2}
$$

This is shown in Fig. 6 for $h_{\mathrm{d} 1}=600 \mathrm{kPa} / \mathrm{m}^{2}$ and the same parameter values for the remainder of the model. 


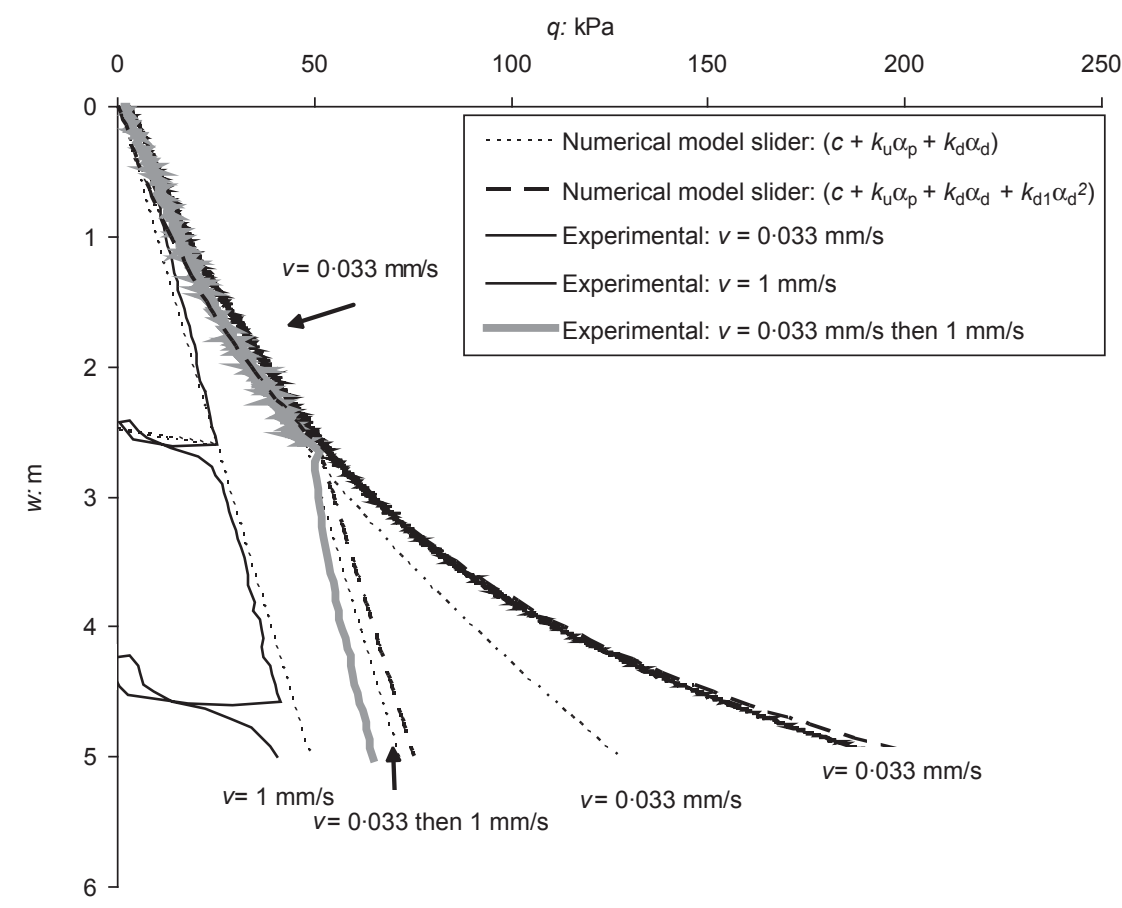

Fig. 6. Comparison of model and experimental data for a spudcan in calcareous silt

\section{CONCLUSIONS}

An analytical model for predicting the behaviour of shallow foundations subjected to different load rates is proposed. The model is based on a simple mechanical approach and provides a unified formulation for the prediction of shallow foundation behaviour under drained, partially drained and undrained conditions. The calibration procedure for the parameters describing the purely vertical model is described, with examples of simulating the penetration of a T-bar and a spudcan at different rates showing close match to results measured in a geotechnical centrifuge. The model can be extended to include horizontal load as well, and the hyperplasticity formulation for this is described in the accompanying annex to this paper.

\section{Acknowledgements}

The second author acknowledges support for this research from the Australian Research Council through their Future Fellowship and Centres of Excellence Programmes and from The Lloyd's Register Educational Trust.

\section{REFERENCES}

Bienen, B., Byrne, B. W., Houlsby, G. T. \& Cassidy, M. J. (2006). Investigating six degree of freedom loading of shallow foundations on sand. Géotechnique 56, No. 6, 367-379.

Cassidy, M. J. (2003). Drum centrifuge model tests comparing the performance of spudcans and caissons in calcareous silt. Centre for Offshore Foundation Systems, University of Western Australia, Geo:03306.

Chung, S. F., Randolph, M. F. \& Schneider, J. A. (2006). Effect of penetration rate on penetration resistance in clay. J. Geotech. Geoenviron. Engng ASCE 132, No. 9, 1188-1196.

Doherty, J. P. \& Deeks, A. J. (2003). Elastic response of circular footings embedded in a non-homogeneous half-space. Géotechnique 53, No. 8, 703-714.

Finnie, I. M. S. (1993). Performance of shallow foundations in calcareous soil. $\mathrm{PhD}$ thesis, University of Western Australia.

Garnier, J., Gaudin, C., Springman, S. M., Culligan, P. J., Goodings, D., Konig, D., Kutter, B., Phillips, R., Randolph, M. F. \& Thorel, L. (2007). Catalogue of scaling laws and similitude questions in centrifuge modelling. Int. J. Phys. Mod. Geotech. 7, No. 3, 1-24.

Hodder, M. S. \& Cassidy, M. J. (2010). A plasticity model for predicting the vertical and lateral behaviour of pipelines in clay soils. Géotechnique 60, No. 4, 247-263.

Houlsby, G. T. \& Cassidy, M. J. (2002). A plasticity model for the behaviour of footings on sand under combined loading. Géotechnique 52, No. 2, 117-129.

Houlsby, G. T. \& Puzrin, A. M. (2006). Principles of hyperplasticity: an approach to plasticity theory based on thermodynamic principles. London: Springer.

House, A. R., Oliveira, J. R. M. S. \& Randolph, M. F. (2001). Evaluating the coefficient of consolidation using penetration tests. Int. J. Phys. Mod. Geotech. 1, No. 3, 17-25.

Martin, C. M. \& Houlsby, G. T. (2001). Combined loading of spudcan foundations on clay: numerical modeling. Géotechnique 51, No. 8, 687-700.

Poulos, H. G. \& Davis, E. H. (1974). Elastic solutions in soil and rock mechanics. New York: Wiley.

Randolph, M. F. \& Hope, S. (2004). Effect of cone velocity on cone resistance and excess pore pressures. Proc. Int. Symp. Engng Practice and Performance of Soft Deposits, Osaka, 147152.

Schneider, J. A., Lehane, B. M. \& Schnaid, F. (2007). Velocity effects on piezocone measurements in normally and over consolidated clays. Int. J. Phys. Mod. Geotech. 7, No. 2, 23-34.

Yafrate, N. J. \& DeJong, J. T. (2007). Influence of penetration rate on measured resistance with full flow penetrometers. Proc. ASCE GI GeoDenver Conf., Denver, CO.

\section{WHAT DO YOU THINK?}

To discuss this paper, please email up to 500 words to the editor at journals@ice.org.uk. Your contribution will be forwarded to the author(s) for a reply and, if considered appropriate by the editorial panel, will be published as a discussion. 